exclusive province; a minority were extensions of intracranial tumours, or could be determined pre-operatively to have intracranial extensions and obviously were not.

For the remainder I feel with previous correspondents that lack of ophthalmic enterprise has led the neuro-surgeons to place their claims too high, and would suggest that the transfrontal approach for purposes of diagnosis or tumour removal is only indicated where the tumour interferes with the function of the optic nerve (not the macula), and is probably situated at the orbital apex, or far back on the inner side.

As the general surgeon is not so careful about the condition of instruments as ourselves, I have found it advisable to inspect those borrowed two or three weeks before operation, so that they can be put in order in time.

Yours faithfully,

JOHN FOSTER.

LEEDS

OBITUARY

\title{
ANDREW MAITLAND RAMSAY, 1859-1946
}

AnDRew Maitland Ramsay died at St. Andrews on March 20, 1946, in his eighty-sèventh year. $\mathrm{He}$ was born in Glasgow on November 9, 1859, and was educated at Linlithgow Burgh Grammar School and the University of Glasgow. $\mathrm{He}$ was a great clinical ophthalmologist after the manner of William Mackenzie in whose steps he walked and whom he greatly admired. In 1882 he graduated M.B., C.M., and obtained the higher qualifications of M.D. and F.R.F.P.S. during the next ten years. Later he became an LL.D. (honoris causa) of his old University and a Fellow of the Royal Society of Edinburgh. His early graduate experience was obtained in the Western Infirmary, Glasgow, and in the Glasgow Eye Infirmary. There he came under the influence of Gavin Tennent, and Thomas Reid. His experience was enlarged by a period in general practice prior to his devoting himself to his chosen speciality. Throughout his long life he retained an admiration and devotion to his early teachers in the ancient University and in his turn added to the clinical traditions which he admired so much.

In the wider field of British Medicine he had many personal friends particularly Osler and James Mackenzie. The main belief of these great clinical obervers that laboratory work of all kinds must take second place to the patient received wholehearted support 
Band-shaped corneal degeneration. Haem. Eos. $300 \times$. 1. Acidophil amorphous mass. 2. Pinkish fluid. 3. Calcified Bowman's membrane. 4. Epithelium growing between gaps of broken Bowman's membiane. 5. Lime powder in corneal lamellae. 6. Acidophil structureless substance.

FIG. 1. 
Band-shaped corneal degeneration. 300X. Mallory. Note:-1. Dark blue calcified Bowman's membrane broken up. 2. Intensive acidophil substance in front of Bowman's membrane between epithelial cells (stained differently from orange red blood corpuscles).

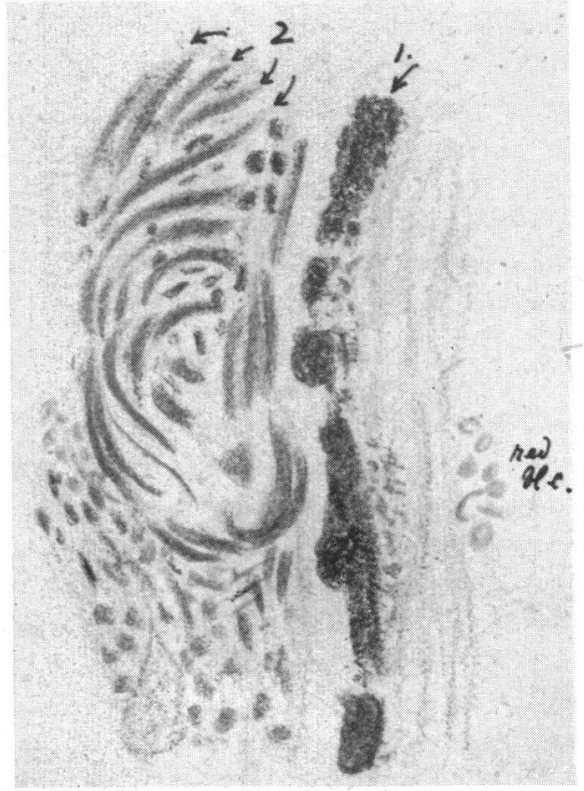


Band-shaped corneal degeneration. 300×. H.E. Note:-1. Acidophil granular substance in front of Bowman's membrane. 2. Parallel splitting of Bowman's membrane. 3. Unequal distribution of lime in main mass of Bowman's membrane.

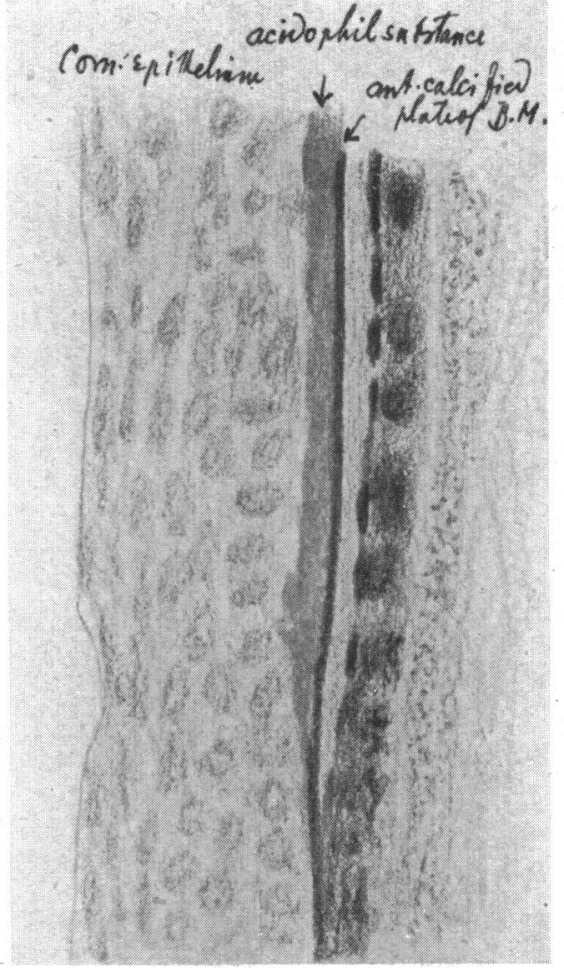


Band-shaped corneal degeneration. $300 \times$. H.E. Note:-subepithelial connective tissue. Epithelium thinned.

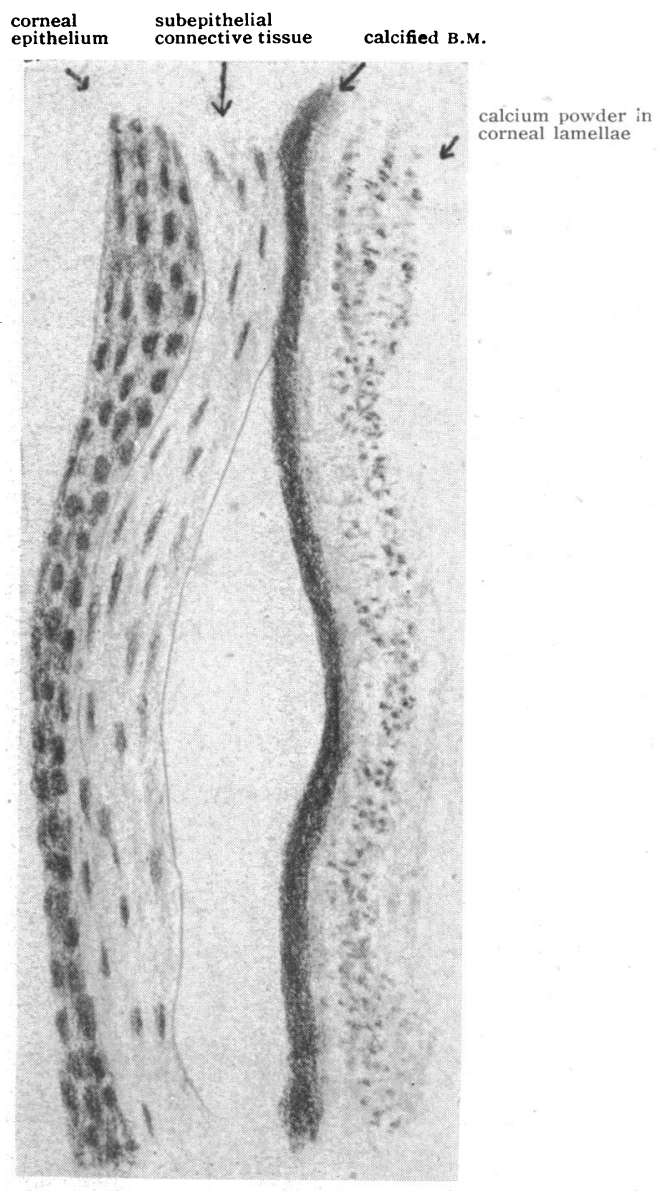

FIG. 4. 


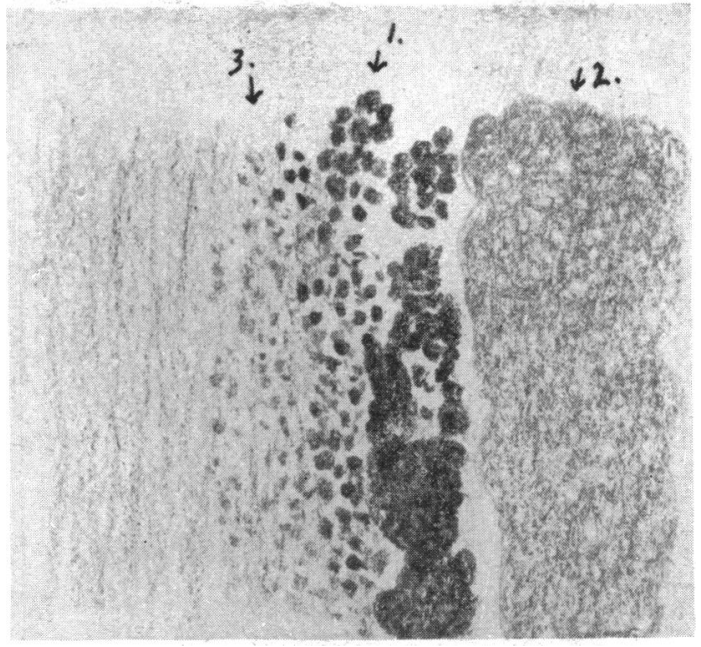

D.

FIG. 5

Band-shaped corneal degeneration. von Kossa's reaction. 1. Lime granules brownish-black. - 2. Acidophil substance safranin red. 3. Red granules between calcium positive masses.

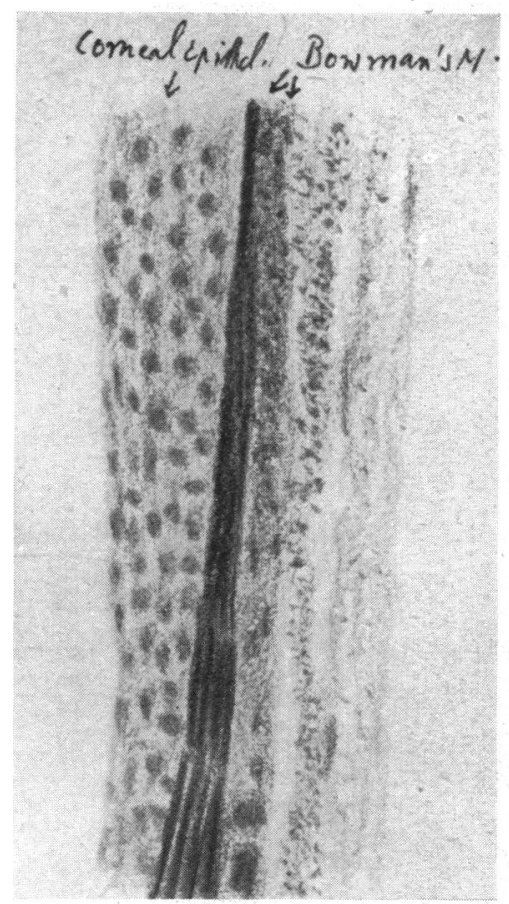

Fig. 6.

Band-shaped corneal degeneration. 300X. Gel. H.E. Note:-1. Anterior part of Bowman's membrane split into 5 layers. 2. Posterior $3 / 4$ more granular. 3. Anterior lamellae are purplish powdered. 


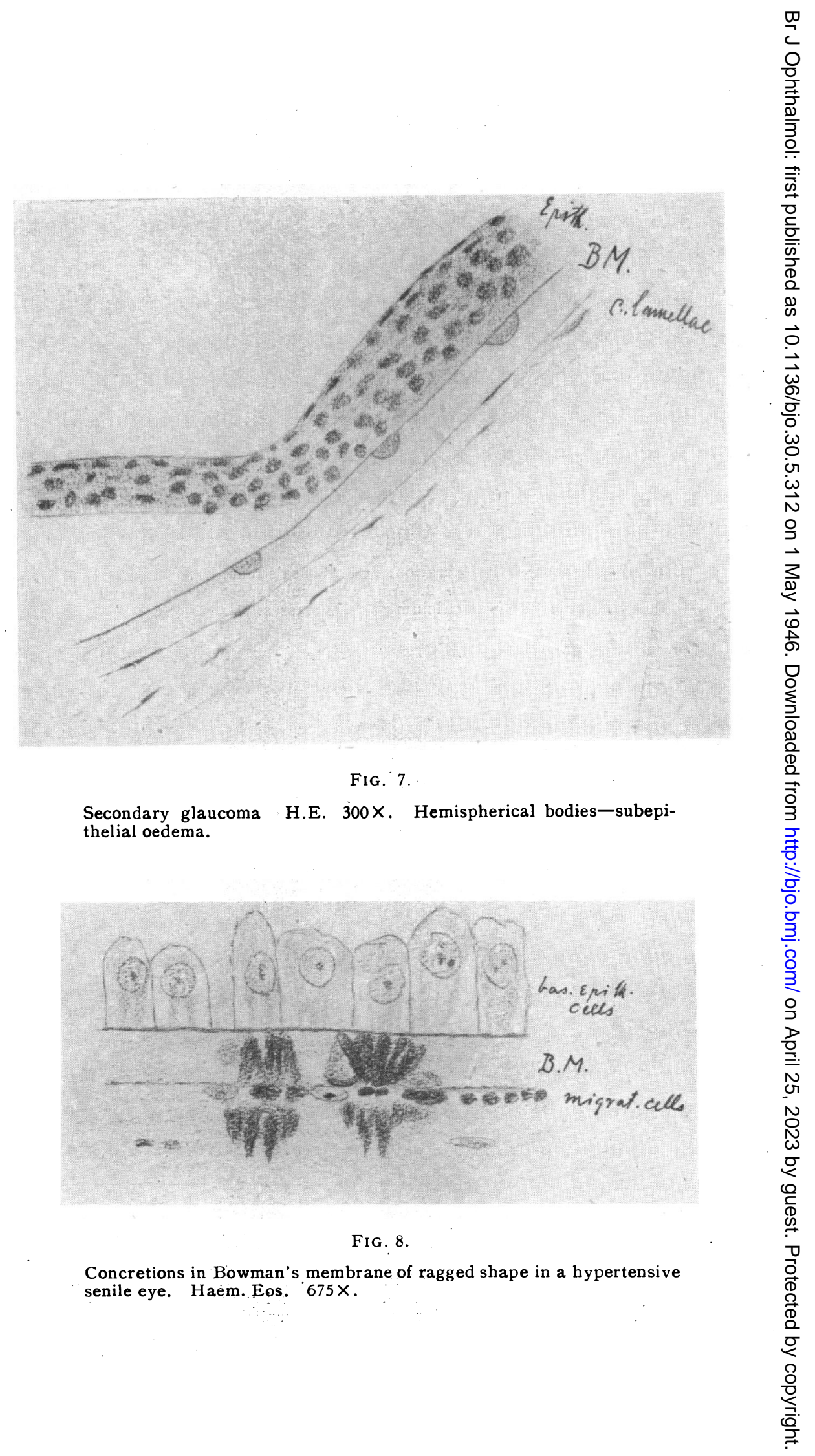




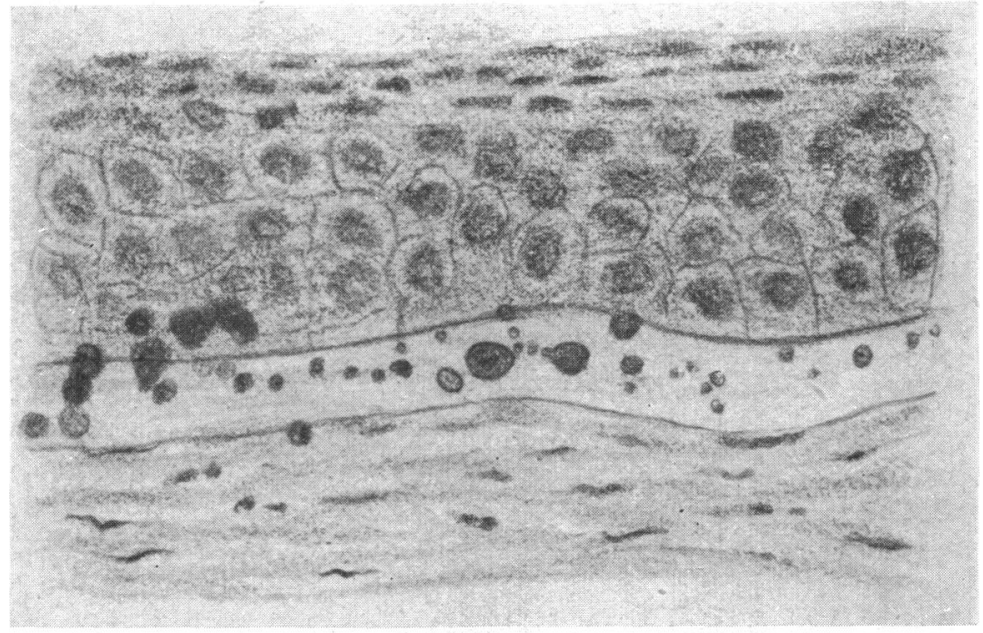

FIG. 9.

Concretions in Bowman's membrane and basal epithelial cells in a hypertensive senile eye. Haem. Eos. 675X. Note:-Most of the concretions are purplish, some of them have an orange appearance.

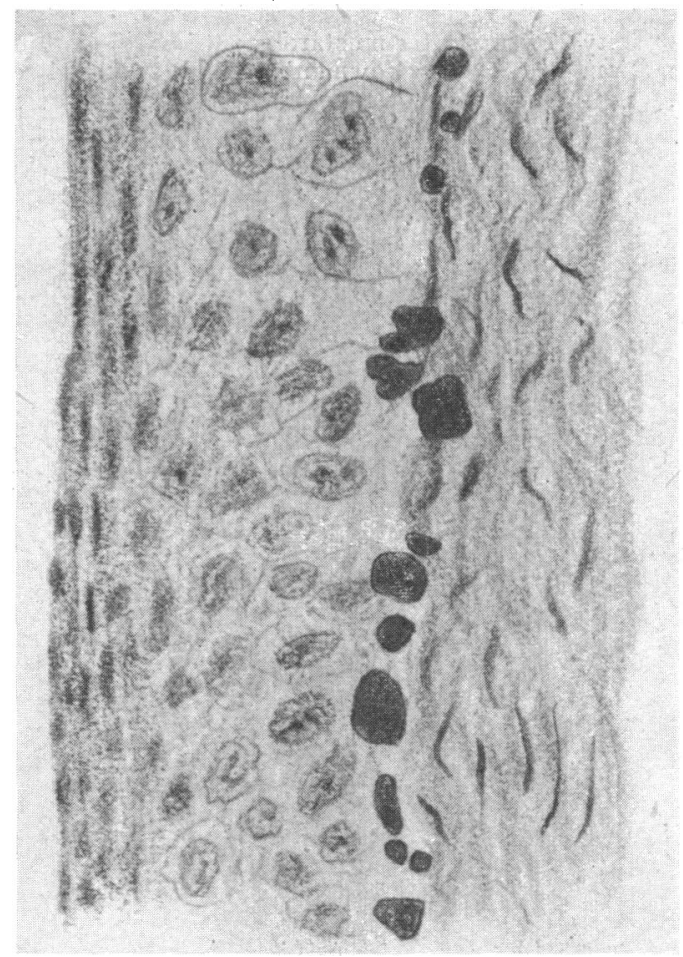

FIG. 10 .

Concretions in scleral conjunctiva. H.E. 600X. Most of them are in basal cells towards sclera. They are embedded in sclera as well. 


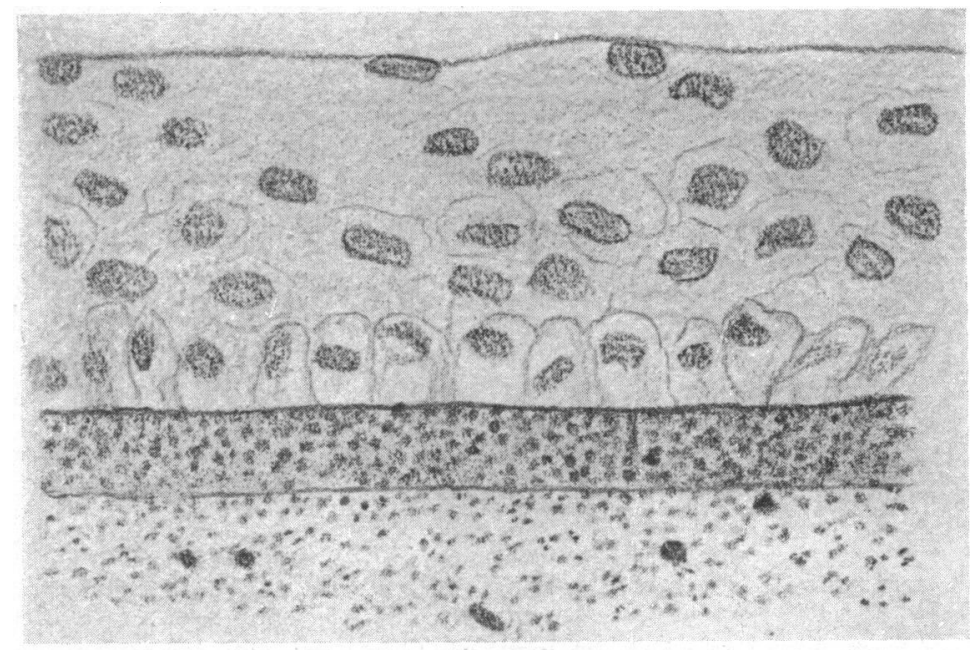

Fig. 11.

Corneal opacity 27 years after mustard gas injury of both eyes. H.E. Oil immersion. 675 $\times$. Bowman's membrane full of purplish granules. Epithelium free: Corneal lamellae powdered. 
from Ramsay. He was a sturdy individualist and with certain forms of modern research he had little sympathy, believing that the out-patient department and the bedside must be the centre of enquiry to which every other interest must be subordinated.

$\mathrm{He}$ was a man of varied interests and tireless activity all his days. During his early clinical years at the Charlotte Street Dispensary of the Glasgow Eye Infirmary he collected material for his Atlas of External Diseases of the Eye which was published in 1897. This is still a standard work and the beautiful plates retain their freshness and value to this day. Photographs, drawings, lantern slides and teaching apparatus of all kinds were of life-long interest to him and he was an inveterate collector of clinical data beautifully illustrated with material from his experience. In 1898 he was appointed Surgeon to the Ophthalmic Institution, the Eye Department of the Glasgow Royal Infirmary. The Ophthalmic Institution was founded by J. R. Wolfe, who practiced ophthalmology for many years in Glasgow and whose name has been known to generations of surgeons in relation to skin-grafting. The building was an old one and Ramsay had the great hope that it would be re-built and closely integrated with the work of the Royal Infirmary and the medical wards which he loved so much. This hope was not fulfilled, however, and the old building is still in use. In it he inaugurated post-graduate activities of a varied character, particularly lectures to physicians and general practitioners. These courses were attended enthusiastically and he took the greatest pains in the preparation and delivery of each lecture. Many have been published in the various medical periodicals and the most valued were reprinted in book form.

During the 1914-1918 war he served as a Major, R.A.M.C. (T.), being attached to the 3rd Scottish General Hospital as ophthalmic surgeon. It was at this time that under the will of his old friend and teacher, Gavin Tennent, the University of Glasgow received a bequest for the foundation of a Chair in Ophthalmology. The subject had received academic recognition as far back as 1828 when William Mackenzie was appointed Lecturer in Ophthalmology; he died in 1869 and was succeeded by Thomas Reid, who was followed by Ramsay. The tragedy of war and the subsequent difficulty in building prevented the fulfilment of the project for over twenty years. He lived to see his successor as Lecturer installed as the first occupant of the Chair in 1936. Within three years of its foundation the world was plunged into the second war.

Many honours and distinctions were conferred upon Ramsay throughout his long life. He was President of the Ophthalmological Society of the United Kingdom in 1922 and of the Ophthalmological Section of the British Medical Association at its meeting in Bradford. He was the first recipient of the William Mackenzie 
Medal and was a President of the Glasgow Royal Medico-Chirurgical Society. He retired from active hospital work at the age of sixty and went to live in St. Andrews. His enthusiasm for clinical activities of all kinds found fitting expression in his devotion to the Mackenzie Institute for Clinical Research which had been founded by his friend, Sir James' Mackenzie in St. Andrews. The published reports of the Institute bear witness to the thought and energy which Ramsay put into a project which had such a close parallel in clinical medicine to his own ideals in clinical ophthalmology. Both the Tennent Institute and the Mackenzie Institute had to curtail their activities in 1939 but fortunately neither suffered great material damage. The Charlotte Street clinic where Ramsay worked so hard as a young man was destroyed by enemy action.

From his beautiful home in St. Andrews he retained his ophthalmological contacts and interests to the end. He was in correspondence with many friends and colleagues throughout the world, and the hospitality of Dr. and Mrs. Maitland Ramsay was a feature of the most academic town in Scotland. He was always pleased to hear of fresh activities in the world of ophthalmology and was delighted to yarn by the fireside on the events of the past and the plans for the future. The trend of modern medicine was in general distasteful to him. He feared the bureaucrat and the organiser of clinical work. Anything which was in the least likely to interfere with the personal relationship between the patient and a trusted medical adviser was anathema to him, and rightly so. Patients loved him and he gave himself wholeheartedly to their service; even after his retirement from active practice in Glasgow, many made the journey to St. Andrews to consult with one of ripe wisdom and wide culture. The charm and geniality of his manner will long be remembered by the generation of students whom he trained; the generations to come will read the papers of a great clinical observer with benefit and understanding. He applied in his practice the best that is known in our art and maintained throughout his long life an enthusiasm for ophthalmology that has been an inspiration to his younger colleagues.

\section{JOHN ALEXANDER PRINGLE}

John Alexander Pringle, Hon. Ophthalmic Surgeon to the Kent and Canterbury Hospital, who died at Epsom on February 12, was born in Ireland, Co. Tyrone, in 1882, and was educated at Coleraine Academy, at the Royal Academy, Belfast, and at Trinity College, Dublin. He graduated in medicine in 1905, and proceeded M.D. of Dublin University in 1908 after holding house appointments in Dublin and at the Bristol Eye Hospital. Coming to London he worked as chief assistant at Moorfields and senior 